\title{
Construindo caminhos e chegando ao fim da linha? Trabalho e trabalhadores da Transamazônica
}

\author{
Building paths and reaching the end of the line? Work and \\ Transamazônica workers
}

Magno Michell Marçal Braga*

Palavras chave:

Trabalho

Trabalhadores

Transamazônica
Keywords:

Work

Workers

Transamazônica
Resumo: A rodovia Transamazônica nasceu filiada ao Programa de Integração Nacional (PIN) no auge da ditadura civil-militar em 1970 e teve a incorporação do território amazônico à lógica do capital nacional como pano de fundo da estratégia do Estado, que contava com o Nordeste como área de repulsão de um exército de mão de obra, além de grandes empresários interessados no megaempreendimento de construção civil e nos grandes projetos agropecuários com financiamentos subsidiados. A execução do projeto exigiu a migração de milhares de trabalhadores contratados de maneira direta ou indireta por grandes empreiteiras nacionais ou por intermediários e submetidos a diversos tipos de abusos e desrespeito às leis trabalhistas em vigor no momento. A obra, apesar da subnotificação de casos, fez disparar o número de acidentes de trabalho comunicados às autoridades, além de resultar em um boom de açôes trabalhistas movidas por trabalhadores contra as empreiteiras envolvidas no projeto. Chamados a "construir o Brasil Grande", muitos desses trabalhadores que construíram caminhos e acabaram encontrando o fim da linha de suas próprias trajetórias.

Abstract: The Transamazônica highway was born affiliated to the National Integration Program (PIN) at the height of the civil-military dictatorship in 1970 and had the incorporation of the Amazon territory into the logic of national capital as a backdrop for the State's strategy, which relied on the Northeast as an area of repulsion of an army of labor, as well as large businessmen interested in the mega construction enterprise and in large agricultural projects with subsidized financing. The execution of the project required the migration of thousands of workers hired directly or indirectly by large national contractors or intermediaries and subjected to various types of abuse and disregard for the labor laws in force at the time. The work, despite the underreporting of cases, triggered the number of occupational accidents reported to the authorities, in addition to resulting in a boom in labor lawsuits brought by workers against the contractors involved in the project. Called to "build Brasil Grande", many of these workers who built paths and ended up finding the end of the line of their own trajectories.

Recebido em 31 de maio de 2021. Aprovado em 04 de outubro de 2021.

\footnotetext{
* Licenciado em História (UFPE). Mestre em História do Norte-Nordeste (UFPE). Doutor em História (Universidade de Coimbra). Membro do Centro de Estudos interdisciplinares do século XX da Universidade de Coimbra. Professor do Instituto Federal de Alagoas IFAL. E-mail: magnomichellmarcalbraga@gmail.com.
} 
O que faz andar a estrada? É o sonho.

Enquanto a gente sonbar, a estrada permanecerá viva. É para isso que servem os caminhos, para nos fazerem parentes do futuro.

(Mia Couto)

Como afirma Tuahir, personagem de Mia Couto, as estradas são pensadas como pontes do agora com o futuro sonhado, mobilizadoras do movimento vital. A rodovia Transamazônica, iniciada em 1970, representava muito mais do que um projeto de estrada, pois buscava materializar um grande programa de colonização na Amazônia e a transformação de um território, a construção de uma nova sociedade. Seu público-alvo para executar a colonização da vasta regiáo era, em sua maioria, constituído por migrantes nordestinos, a quem o discurso do Estado buscou convencer de que seria a redenção, e sulistas com dificuldades para encontrar terras em sua região e interessados em trabalhar na expansão da fronteira agrícola. As atividades agrícolas viriam a ser, portanto, o elo entre pessoas de outros lugares do país e a região amazônica.
A obra foi dividida em lotes que seriam executados por construtoras escolhidas através de editais públicos. O primeiro edital foi publicado no dia 20 de junho de 1970, dividiu a primeira etapa da construção em cinco lotes e previa que as empresas vencedoras deveriam "recrutar os trabalhadores na região seca do Nordeste" ${ }^{\text {. As empresas vencedoras }}$ foram as seguintes: Construtora Mendes Júnior (lote 1 e 3); S.A. Paulista Com. E Construçốes (lote 2); Construtora Queiroz Galvão (lote 4); EIT Empresa Industrial Técnica S.A. (lote 5). O contrato foi celebrado em 06 de agosto de 1970 e poucas semanas depois a obra foi iniciada.

A segunda licitação, feita em agosto de 1971 teve a seguinte configuração: Construtora Rabello, no trecho Itaituba - Jacareacanga (lote 6); Construtora Camargo Correa S.A., no trecho Jacareacanga - Rio Aripuanã (lote 7); Construtora Paranapanema, no trecho Rio Aripuanã Humaitá-AM (lote 8) (SOUZA, 2012). Na figura 1 podemos observar a distribuição espacial dos trechos, por empresa construtora.

\section{CONSTRUTORAS DA TRANSAMAZÔNICA POR TRECHO}

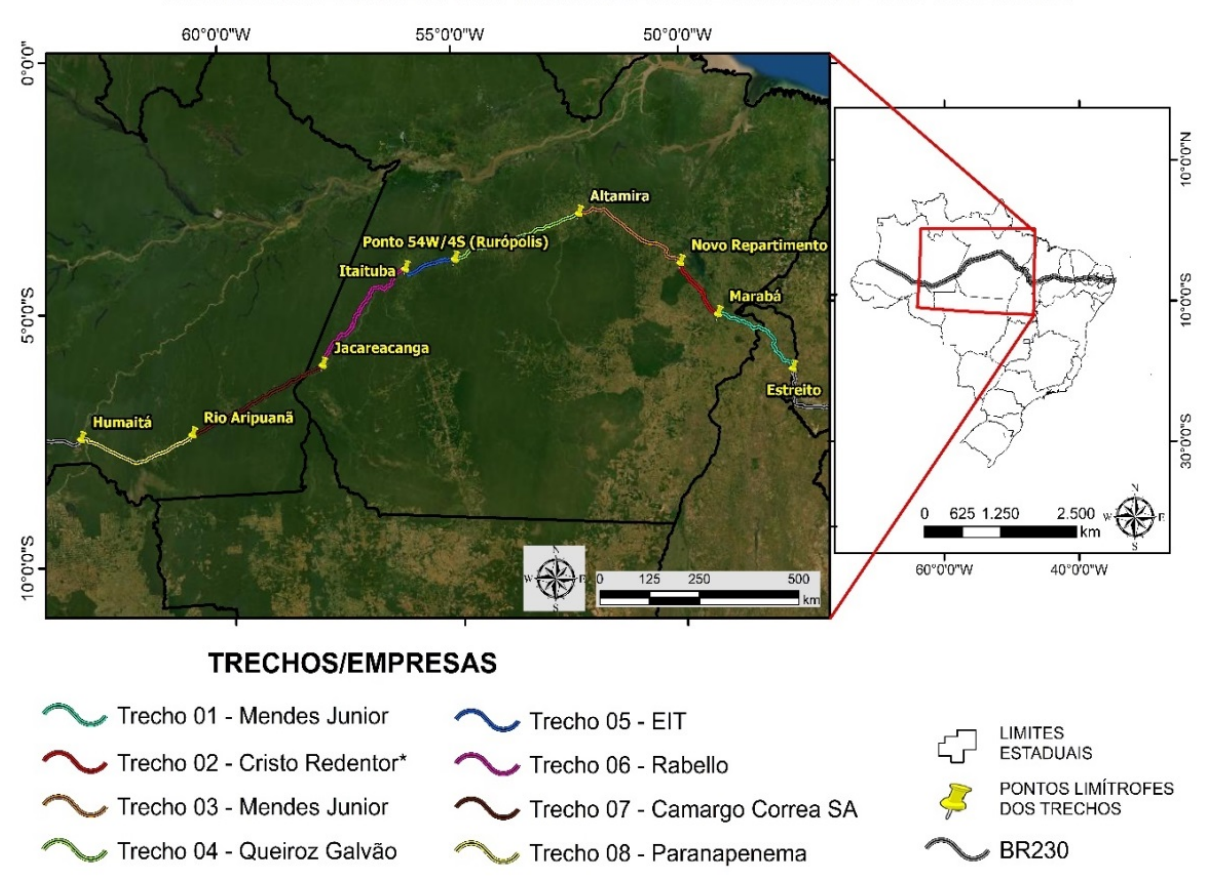

Figura 1 - Construtoras da Transamazônica por trecho.

Autor: Kleython Monteiro. 
Cabe destacar que todas as empresas ganhadoras do processo licitatório eram brasileiras. Isso ocorreu porque havia reserva de mercado, criada em 1969, para garantir que empresas nacionais estivessem ligadas às grandes obras da ditadura. Segundo Pedro Campos,

partindo de uma crítica à política do governo Castello de fazer uso de empresas de engenharia estrangeiras, que vinham atreladas aos financiamentos de organizações forâneas, a mobilização desses empresários conseguiu auxiliar a reorientar as políticas para o setor, tendo como resultado direto a criação de um grupo de trabalho governamental em 1967 e, em especial, um decreto de 1969 que estabelecia a reserva de mercado para construção, projetos e montagem industrial de obras realizadas pelo governo brasileiro a companhias nacionais. Apesar da participação não tão exposta de empresários $\mathrm{da}$ construção pesada, esses foram beneficiários diretos desta medida. (CAMPOS, 2011, p. 302).

O Slogan adotado pelo governo e repetido pelo presidente da República Emílio Garrastazu Médici afirmava que Transamazônica seria uma estrada para garantir "terras sem homens para homens sem terras" ${ }^{3}$. Esta representação da Amazônia como espaço vazio a ser ocupado viria a permear toda a propaganda utilizada pelo Estado para persuadir a opiniáo pública sobre $o$ empreendimento e acarretaria encontros e desencontros entre grupos muito distintos.

A ideia era construir uma obra em formato de espinha de peixe, com uma rodovia principal e, a cada dez quilômetros, estradas vicinais perpendiculares, para atrair populaçôes visando ocupar a Amazônia e proteger a região de um suposto assédio estrangeiro. Assim, a rodovia Transamazônica foi projetada para iniciar em Cabedelo ${ }^{4}$, no Estado da Paraíba, às margens do oceano Atlântico, e terminar na fronteira com o Peru, para conseguir alcançar o oceano Pacífico, em Lima. Teria mais de $5000 \mathrm{~km}$ de extensão. Entretanto, a rodovia se encerra na cidade de Lábrea, localizada no estado do Amazonas.

\section{Trabalho e trabalhadores na Transamazônica}

A primeira etapa do processo de construção da rodovia foi o recrutamento de milhares de trabalhadores de diversas partes do país, em especial do Nordeste, como já previa o decreto de criação do PIN, para executar a obra. O número exato de trabalhadores envolvidos na execução da obra não é de conhecimento público. A falta de transparência que envolvia a coisa pública nos anos de ditadura e a massiva contratação de trabalhadores sem registro dificultam ainda mais uma estimativa. Os dados apresentados pelos boletins informativos $\mathrm{da}$ FUNDACENTRO 5 aqui apresentados não trazem o número de contratados, nenhum dos trabalhos que tratam do tema apresentam tais números, nem foram encontrados dados oficiais. Em informações circuladas pela mídia estimava-se entre 4 e 6 mil trabalhadores, entretanto um texto de Damião Gaspar apresentou números que julgamos mais factíveis. Segundo o texto a gigante obra promoveria "Uma movimentação de terras equivalente a 12 represas como a de Boa Esperança, realizada por 15 mil homens, enfrentando as mais adversas condiçôes na selva amazônica"6.

É com as experiências dos trabalhadores envolvidos no megaprojeto que este trabalho se constrói. Sabia-se, a partir de experiências em grandes obras passadas, que a vida do trabalhador envolvido nesses projetos não é nada fácil e chegou-se a especular a utilização de mão de obra vinda do sistema prisional para garantir formação de contingente de trabalhadores a baixo custo, como noticiou o jornal Correio da Manhã de 14 de outubro de 1970 .

A ideia de utilizar mão de obra do sistema prisional não vingou e os milhares de trabalhadores mobilizados em torno da execução da obra foram contratados ou aliciados em diferentes localidades. $\mathrm{O}$ universo de trabalhadores pode ser dividido entre aqueles que eram vinculados formalmente às grandes empreiteiras contratadas pelo Governo Federal, aqueles que eram contratados formalmente por empreiteiras menores subcontratadas pelas grandes empreiteiras e aqueles que eram aliciados pelos chamados gatos ${ }^{8}$ e que não possuíam nenhum 
tipo de registro legal, mas estavam prestando serviços para alguma das empreiteiras.

Apesar de as grandes empresas ganhadoras das licitações terem efetuado recrutamento em várias localidades do país onde tinham escritórios, também se utilizaram do expediente da subcontratação de empresas para execução de parte da obra e da figura dos gatos para intermediar a contratação de trabalhadores. As consequências das subcontrataçóes, além dos limites legais de sua utilização, como veremos nas páginas subsequentes, foram terríveis para a classe trabalhadora e fizeram surgir uma espécie de subcategoria de trabalhador, mais precarizado, vilipendiado em seus direitos, mais suscetível a doenças, acidentes e morte. Ademais, a maioria dos trabalhadores contratados por intermediários não possuía registro em Carteira de Trabalho e engrossava o caldo das subnotificaçóes acerca de acidentes de trabalho nas estatísticas oficiais.

O caso do aliciamento de trabalhadores pobres chegou a ser noticiado em periódicos. $\mathrm{O}$ Correio Braziliense de 25 de julho de 1973 trazia notícia positiva sobre a atuação do Ministério do Trabalho e Previdência Social na capacitação de trabalhadores da obra da Transamazônica a fim de garantir mão de obra qualificada na região amazônica. No entanto, a matéria trouxe também:
É verdade que existem os "gaiteiros". Elementos responsáveis pelo aliciamento de trabalhadores no Nordeste e em outras áreas que querem emprego na Transamazônica. Esses gaiteiros, porém, de uma forma geral, são despidos de escrúpulos e, ânsia de lucros fáceis, transportam qualquer um que queira ir para as frentes de trabalho da rodovia. Às vezes, sem condiçôes para serem utilizados, quer devido a idade avançada, quer porque são doentes?.

A maior parte dos trabalhadores não qualificados tinha como suas funções desmatar, abrir a picada e auxiliar a chegada dos topógrafos. Esses trabalhadores eram recrutados em seus lugares de origem ou se deslocavam por conta própria para a Transamazônica com a esperança de abandonar a condição social na qual estavam. Um grupo grande desses trabalhadores era migrante interno da própria região ou oriundo do Nordeste, a maioria sem letramento algum e desconhecedores dos direitos legais. Por outro lado, eram conhecedores da luta pela sobrevivência. Movimentar-se no território era a única chance vista por muitos desses sujeitos que acompanharam historicamente os ciclos desenvolvimentistas no Brasil.

\section{ESTADOS DE ORIGEM DA MAIOR PARTE DOS
TRABALHADORES MIGRANTES DA TRANSAMAZÔNICA}

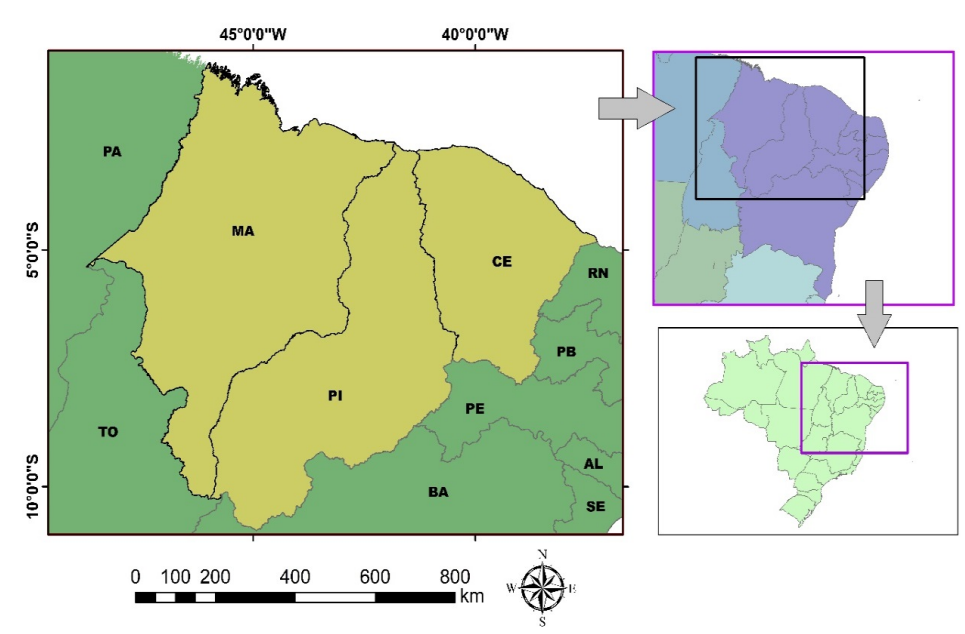

Figura 2 - Estados de origem da maior parte dos trabalhadores da Transamazônica. Autor: Kleython Monteiro. 
As representações feitas destes homens tendiam a caricaturá-los, como vemos em matéria especial publicada pela revista Manchete em 09 de janeiro de 1971. Conforme a notícia, a maior parte dos trabalhadores com baixa qualificação era recrutada nos estados nordestinos do Maranhão, Piauí e Ceará. "Os mateiros, uns 700, são uma gente só. Tudo nordestino do Maranhão, Piauí e Ceará.” (Revista Manchete, 09/01/1971, p. 91 grifo nosso).

Não há dúvida de que os mateiros são homens rudes. Oitenta por cento deles são analfabetos. Os outros soletram alguma coisinha. Andam sempre armados e ao primeiro contato mostram-se bastante arredios. Depois, à medida que vai rompendo a barreira da desconfiança, vão se mostrando como realmente são: ingênuos e infantis. (Revista Manchete, 09/01/1971, p. 93).

Foram essas pessoas, juntamente com as populaçóes indígenas, as que mais sofreram as consequências catastróficas do desenvolvimentismo que Transamazônica representa. Uma obra reprodutora da violência estrutural e do biopoder estatal que que recai pesadamente sobre a classe trabalhadora definindo quem, onde e como se deve viver ou morrer ${ }^{10}$.

No universo de trabalhadores de baixa qualificação que formam a maior parte dos trabalhadores mobilizados por empreiteiras há aqueles que, no curso da atividade laborativa, conseguiram se profissionalizar e alcançar melhores posições na hierarquia do trabalho. Seu Dão ${ }^{11}$ é uma dessas personagens que representariam o "sucesso" do trabalhador na trajetória laborativa:

O meu primeiro serviço na Queiroz Galvão foi britador. Ajudante de britador. É fazendo brita. Fazendo brita. Daí fui... fui crescendo, fui subindo. Com poucos anos eu tava como operador de máquina. [...] Em 74, o DNER, o Incra tava contratando eles. Aí eu fiz o concurso do Incra. O DNER criou o concurso, eu fiz o concurso do DNER. [...] Aí fiquei... fiquei no DNER. De 74, fiquei até me aposentar em 2003. [...] Eu... eu iniciei como operador de máquina, mas logo em seguida... me botaram como encarregado de... de equipe ${ }^{12}$.
Uma vez que grandes obras de infraestrutura mobilizam números muito grandes de trabalhadores e elas, por sua vez, tem data para serem finalizadas, a questão da desmobilização da massa de trabalhadores se torna imperativa nos projetos. No caso da Transamazônica, a parte absorvida pelas instituiçóes públicas como INCRA e DNER foi insuficiente em relação ao número total de desmobilizados. Para garantir a fixação dos trabalhadores na região, o Governo Federal prometia distribuir terras nas margens da própria rodovia, através do INCRA, transformando os trabalhadores em colonos. No entanto, após o término dos trechos muitos eram transferidos para outras obras (na época havia um boom de obras infraestruturais) ou migravam para os centros urbanos, fazendo inchar as pequenas cidades amazônicas e implicando no aumento das demandas sociais de toda ordem.

No caso de Seu Luis ${ }^{13}$, o recrutamento para trabalhar na obra ocorreu em Curitiba, capital do Paraná. Ele passou por uma seleção e, após percorrer as etapas que envolveram uma ida à Belo Horizonte, foi contratado pela empresa Mendes Júnior para exercer a função de mecânico na obra. No entanto, grande parte dos trabalhadores recrutados para a obra da Transamazônica teve outro tipo de experiência.

Seu Edson ${ }^{14}$, um pernambucano que trabalhou como motorista na Construtora Rabello afirmou que "quem trabalhava na empreiteira era registrado. Agora, quem não trabalhava registrado, trabalhava como gato, aí não era registrado, trabalhava avulso". Após a fase de arregimentação dos trabalhadores era necessário fazer o deslocamento de máquina e pessoal para o local da obra.

A chegada de maquinário e a construção do acampamento eram os passos iniciais para garantir condiçôes de alojamento e organização de pessoal para a abertura da primeira picada e marcação topográfica, seguida da derrubada da mata. Os primeiros a caminhar na mata eram os auxiliares de topógrafos, topógrafos e mateiros que abriam a picada e faziam a marcação para a chegada das máquinas e demais trabalhadores. A maior parte das obras de construção se dava em área de floresta, cercada por centenas de quilômetros de mata densa, rios e igarapés, por isso o acesso inicial se dava pelo 
caminho das águas. Os trabalhos se iniciavam com a abertura de uma clareira na mata onde seria construído o acampamento. Estes, por sua vez, eram compostos de barracôes, onde se construíam as oficinas, a cantina e o refeitório que preparava e servia as alimentaçóes e o alojamento para descanso, normalmente composto por uma lona e madeiras fincadas no chão para servirem de base para montagem das redes. Em muitos casos improvisava-se uma pista para pouso de pequenas aeronaves que tinham a função de transportar autoridades, chefias do canteiro de obras, notícias, suprimentos e doentes ou acidentados graves.

Seu Pedro ${ }^{15}$, que já havia trabalhado na construção da rodovia Belém - Brasília pela Rodobrás, atuou na Transamazônica pela empresa S/A Paulista como ajudante de máquinas e descreveu o acampamento do canteiro de obras:

Naquele tempo que tudo era difícil, é a mata, né, era o alojamentão, fazia... do começo era até de lona e nós entrava [sic] pra debaixo, depois quando era... já na cidade, já... mais... já fazia um barracão de... brasilit, madeira.... Porque aquilo ali era... Era provisório. Dali nós já ia [sic] mais pra frente, tocando a rotina ${ }^{16}$.

Fazer chegar grandes tratores, como os Carterpillar D-8, até o ponto da obra foi um dos problemas encontrados pelos empreiteiros. Para superar as dificuldades foi montada uma logística de guerra. Parte do maquinário chegava desmontado e era remontado no canteiro de obras, todavia essa operação encarecia e atrasava o cronograma da obra. A solução, segundo Wilson Quintella ${ }^{17}$, foi dada pela própria empresa norte-americana: "transportar os tratores montados em barcaças de desembarque utilizadas pelos aliados na invasão da Normandia no dia $\mathrm{D}$, que estavam disponíveis como sobras de guerra e custavam uma pechincha" (QUINTELLA, 2008, p. 268). Neste caso, segundo Quintela, um navio cargueiro partiu da Flórida, nos Estados Unidos, com os tratores e rebocando as barcaças que foram utilizadas no transporte local do maquinário.

\section{Trabalho e trabalhadores na Transamazônica}

$\mathrm{O}$ isolamento continuado por meses, a ausência das famílias, a falta de atividades de lazer nas horas de ausência de serviço e a dificuldade de manter relacionamentos sexuais configuraram um ambiente de pressão psicológica que por vezes desencadeou conflitos mais sérios.

A não definição por parte dos responsáveis pelas firmas empreiteiras de espaços e momentos para o não-trabalho tem sido uma regra com poucas exceçôes ao longo da trajetória histórica do trabalho. Gustavo Lins Ribeiro chama a atenção para este fato que ganha destaque em grandes obras, como a que estudamos:

\begin{abstract}
A utilização por parte do operário do tempo de não-trabalho como tempo de lazer não entra necessariamente nos cálculos dos capitalistas individuais como algo necessário para a manutenção e reprodução da força de trabalho. Isto é ainda mais visível quando se trata de utilizar uma força de trabalho por um período definido a priori, em uma situação tão específica quanto a de um território de construção de um grande projeto no qual, para se oferecer maiores prestações de serviço, são necessários grandes investimentos. (RIBEIRO, 2008, p. 216).
\end{abstract}

A fala de Seu Dalvâneo ${ }^{18}$, engenheiro que chefiou uma turma de trabalhadores, permite ao historiador fazer abstrações acerca do ambiente psicológico experimentado pelos sujeitos envolvidos na obra:

Operário, operário braçal a gente levou daqui (Nordeste), topógrafos, niveladores, auxiliares, gente pra trabalhar no escritório, não tinha ninguém. Era recrutar daqui e levar pra lá. Teve gente que trabalhou comigo que matou gente, teve gente que tocou fogo em avião, ficou doido, pirou. Ficava isolado lá muito homem junto e a diversão era tomar cachaça. [...] Teve um que pirou que eu tive que trazer ele aqui sedado. Ele ficou perturbado, rapaz. Aí eu tive que dá uns calmantes pra ele. Resumindo, eu viajei com ele de avião, dormi com ele lá em Belém e vez por outra botava um cachetizinho na boca dele pra ele ficar meio doidão, meio sedado porque ele tinha sido 
recrutado aqui e eu tinha que entregá-lo aqui (Pernambuco). [...] Eu contratei um índio, meio safado, mas só pra fazer, pra ser caçador. Interessante que quando ele chegava assim à tardinha aí a gente falava "tem nada hoje não pra sopa?” Ele entrava no mato nu, ele tinha assim essa psicose. Ele já tava... é... mais ou menos civilizado. Ele tirava a roupa não demorava muito tempo ele vinha com a caça. O bicho é jeitoso. [...] Quando você tá numa situação dessa você tem que se nivelar com o pessoal, senão você não tinha como ter um certo controle. Ia ser na força? Não podia ser. Claro que eu andava armado, lá todo mundo andava armado. Eu tinha dois revólveres, só andava com meu 38 de lado. Atirei como o diabo. E tinha outras armas mais pesadas lá no acampamento. Mas pra gente conseguir alguma coisa tem que ser, tem que se dar as mãos, senão você não consegue tanger esse povo ${ }^{19}$.

O depoimento de seu Dalvâneo é rico em informações e significados. Deixa claro que a grande parte dos trabalhadores era contratada na região Nordeste e levada para floresta pela própria empresa contratante.

Também deixa escapar a visão hierarquizada que possui acerca dos trabalhadores "braçais". O engenheiro constrói sua identidade na medida em que se distancia dos demais sujeitos envolvidos na obra. "Operário braçal”, "pessoa que matou gente", “tocou fogo em avião", "ficou doido", “pirou”. Sua fala também joga luz sobre a pressão psicológica a qual estavam expostos os trabalhadores envolvidos.

Os trabalhadores braçais são descritos como personagens limitados em sua razão, que precisam ser "tangidos”. Quando diz "você tem que se nivelar com o pessoal" expõe a hierarquização naturalizada por si. Há, todavia, um conjunto de lógicas e valores que os tornam até certo ponto compreendidos, já que cita a necessidade de flexibilizar, negociar com os trabalhadores quando destaca o tempo de isolamento e as formas de superá-lo, como com o uso de bebidas alcoólicas, normalmente proibidas oficialmente, mas toleradas como escape e alívio das tensões, o que por vezes poderia se reverter no contrário, incrementando situações de conflito como os descritos pelo próprio engenheiro.

$\mathrm{O}$ outro personagem que aparece na fala de Seu Dalvâneo é o indígena contratado para caçar. Este, por sua vez, é apresentado como o outro mais distante que os encontros e desencontros da fronteira fazem ver. Incompreendido na forma de ser e animalizado.

A estrutura dos acampamentos variava de acordo com a empresa construtora e demanda por trabalhadores no trecho. As grandes empreiteiras mantinham uma base maior, com o mínimo de estrutura necessária, como posto médico, pistas de pouso e escritórios. Nos acampamentos construídos para atender pequenas demandas, como a construção de pontes pequenas, as estruturas eram mais precárias e temporárias. Em seu romance memorialista $A$ ponte sobre o rio Tuerê, John Coninghan Netto, que trabalhou na construção de pontes da Transamazônica, descreve os acampamentos:

Os nossos subempreiteiros, os lavradores de madeira e os caçadores e pescadores que mantêm os acampamentos supridos de carne, constroem seus próprios barracos nas proximidades, e alguns deles tem mulheres. [Vivem] cerca de vinte nos canteiros das pontes menores, mais de cem, às vezes, nas maiores. É assim: conforme vamos terminando as pontes pequenas em setembro, outubro, os homens são pagos - só pagamos quando está pronta a ponte - e então os levamos de caminhão para Marabá, dando-lhes 15 dias de folga. De lá, os que tem família tomam o ônibus para Carolina ou Imperatriz no Maranhão - de onde vem a maioria deles - e os que não tem, ou cujo pessoal more longe demais, em estados como Ceará, por exemplo, gastam seu dinheiro em Marabá mesmo, geralmente na zona. Quando voltam - alguns precisando de tratamento para gonorreia - são designados para ajudar a terminar as pontes maiores. (CONINGHAN NETTO, 2000, p. 26-27).

Do trecho citado, é possível depreender uma série de características da obra e da rotina dos trabalhadores envolvidos. Dentre elas destacamos as seguintes: 1- Adoção do sistema de subempretagem que tende a extrapolar os limites legais da exploração da força de trabalho e dificulta a punição dos agentes envolvidos; 2- Fica evidenciado que aos trabalhadores subempreitados não estava disponível lugar nos acampamentos oficiais uma vez que, "constroem seus próprios barracos nas proximidades"; 3- A predominante presença masculina nos 
acampamentos; 4- A origem nordestina da maior parte dos trabalhadores menos qualificados que eram do Maranhão ou Ceará.; 5- A relação entre a construção da rodovia e o crescimento das zonas de meretrício das cidades e vilas do entorno da obra e a circulação de doenças sexualmente transmissíveis entre os trabalhadores.

\section{A Alimentação}

Suprir de alimentação um exército de trabalhadores com alta necessidade calórica e no meio da floresta amazônica foi um dos grandes obstáculos enfrentados na execução do projeto Transamazônica. A oferta de alimentos nos acampamentos por parte das empresas era limitada, o que normalmente implicava na necessidade de recorrer à caça para suprir as necessidades de proteína de trabalhadores que enfrentaram um regime duro de trabalho, com turmas que se revezavam vinte e quatro horas por dia nos tempos da estação seca.

Em um acampamento visitado pela reportagem da Revista Manchete em 1971, a carência alimentar era mitigada pela caça. Segundo reportagem de Atenéia Feijó:

A comida depende muito do caçador - e a companhia construtora tem até isso contratado. Carne de boi só uma vez por semana, vinda de uma fazenda longínqua, do outro lado do rio. Não há verdura de espécie alguma. Quando seu Antônio, o caçador, não mata bicho algum a solução é o jabá (carne seca com farinha). Para a cozinheira caça é o mais difícil de preparar. (Revista Manchete, 09/01/1971, p. 86).

Seu Raimundo ${ }^{20}$, que trabalhou como operador de motosserra subcontratado da Construtora Rabello, afirmou que a comida

era peão que fazia, né?! Que num tinha mulher, num tinha ninguém pa [sic] fazer. Era o cozinheiro que fazia... era... aquela comida... grosseira. Mas você tinha que comer, que senão tu ia passar fome, ia morrer de fome, né?! Dento da mata [sic]. E também, carne de caça. Carne de caça, que tinha um caçador que matava caça pra gente comer ${ }^{21}$.

Os relatos dos trabalhadores acerca da alimentação nos acampamentos deixam transparecer que normalmente estavam submetidos à alimentação com sérias restrições nutritivas e em condiçôes precárias de preparo e consumo.

Apesar da notória dificuldade em se criar condiçôes mínimas para o exercício da atividade laboral no meio da floresta, o que justificaria o improviso de instalaçóes como a cantina nos primeiros dias de trabalho, o permanente improviso com o qual lidavam os trabalhadores aponta para o tratamento imposto ao conjunto dos trabalhadores por parte das empreiteiras. Essas gentes, caricaturada por agentes do Estado, da mídia e alguns outros setores da sociedade como "uma gente só" ${ }^{2}$, eram duplamente sobreviventes - no lugar de origem e no lugar de chegada.

Seu Edson descreve um cenário muito semelhante ao que foi descrito por seu Luis:

São seis meses sem comer carne, só conserva. Era sardinha, aí depois eles inventaram uma tal de almôndega, depois teve uma tal de salsicha. Quando eles mandavam salsicha aí os peão [sic] botavam até nome nas salsichas. Quando chegava comida a gente já sabia o gosto... Aquele cheiro... Além de ser conserva, era mal feita! Era. Comia pra não morrer. Lá a gente não tinha outra opção, ou comia ou passava fome. Então a conserva que tinha ninguém aguentava mais. Então comia feijão com arroz. E o engenheiro que trabalhava lá com a gente era muito rígido. Ele tinha muito medo que o peão adoecesse. Só que a empresa não era dele. Ele era chefe só, do setor... Teve uma vez que ele pegou uma panela lá cheia de jabá e jogou no meio da rua dizendo que peão não podia comer aquilo porque aquilo ia adoecer o peão que comesse. Tinha um fardo e meio de jabá.

De maneira geral, as condições de alimentação eram impróprias, mas ainda podia ser pior. Os trabalhadores subcontratados tinham ainda menos assistência. Seu Dão, que trabalhou na Queiroz Galvão, nos disse: 
Vixe, e depois eu ajudei eles [sic] (os subcontratados) demais da conta, que era um sofrimento pra aquele pessoal. Eles não tinham transporte, eles não tinham como trazer alimentação pra... as máquinas tavam [sic], vamos supor, as máquinas tavam [sic] aqui no $40 \ldots$ lá no quilômetro $40 \ldots$ e eles tavam [sic] trabalhando aqui no 80. Quarenta quilômetros de a pé [sic] com a coisa nas costas, trazendo rancho (alimento) pra eles. Era um sofrimento... para aqueles homens ${ }^{23}$.

A fala de Seu Dão joga luz sobre as condições de trabalho e sobrevivência de um exército de trabalhadores que, sem vínculos formais com as empresas contratantes, estavam entregues à própria sorte. Caminhar dezenas de quilômetros durante o dia, sob o sol e a umidade amazônica não é tarefa fácil para o mais saudável e nutrido dos homens e se tornava um calvário para os trabalhadores mal alimentados que caminhavam carregando suas "trouxas" nas costas. A experiência de classe nessas condições extremas às quais estavam expostos, como já demonstraram estudos anteriores ${ }^{24}$, costumam influenciar também na construção de laços de solidariedade e na construção de estratégias para sobreviver da melhor maneira possível. Caronas e partilha do rancho (comida) eram formas de fazer suportar as dificuldades.

Há, todavia, de se salientar que as condições mais precárias às quais estavam expostos os trabalhadores aliciados e subcontratados eram percebidas nas mais diversas questões, desde uma má alimentação que implicava na conformação de corpos mais frágeis e vulneráveis às doenças (entre elas a devastadora malária), passando pela questão de deslocamento e acomodação e finalizando nos níveis de exposição diferenciados aos riscos de acidentes de trabalho e morte.

\section{Acidentes de Trabalho}

Os acidentes de trabalho também faziam parte do cotidiano da massa trabalhadora mobilizada em torno do projeto. Chamamos a atenção novamente para a diferenciação entre os trabalhadores ligados formalmente às grandes construtoras e aqueles subcontratados através de pequenas empresas ou intermediadores. Os últimos raramente entram nos dados estatísticos sobre acidentes de trabalho, uma vez que

nas séries históricas de acidentes de trabalho, apenas os acidentes que foram notificados ao sistema público através do CAT (Comunicação de Acidente de Trabalho) foram contabilizados e utilizados como base para políticas públicas, o que só foi modificado a partir de 2007. (SILVA, 2019, p. 22).

O setor da construção civil no Brasil é historicamente um dos setores em que mais se nota a subnotificação de acidentes de trabalho. Parte dessa subnotificação se dá por causa do alto número de trabalhadores sem registros oficiais. Alguns trabalhadores que conversaram conosco prestaram serviços na construção da Transamazônica na forma de subempreitados e outros contratados com registro na carteira de trabalho. Seu Raimundo, contratado através de gatos pela construtora Rabello, recorda assim de sua experiência:

No tempo eles num [sic] falavam nada de direitos trabalhistas e com os pobres que eles arranjaram ela [sic] só fazia contrato, não fichava carteira nenhuma de ninguém. [...] Você pegava, você é dono da Rabello, pegava a empreitada e então você passava pra meia. A meia já passava pra outro, num trecho pegava oito gato, (grifo do autor) até que chegasse de um pro outro, pro outro, nós já tava passando fome. [...] De vez em quando morria gente. Um amigo meu morreu, ele cortou a perna com a motosserra, num foi indenizado, num foi nada e... quem era contrato, quando o cara chegava a família nem sabia pra onde que o cara tava, aí ficava por lá e enterrava na beira da pista. [...] Ele (Médici) que foi inaugurar Rurópolis, que nós tava lá e fizeram até uma festa. Eu num fui porque tinha furado o pé. E uma, eles (empresa) não davam nem bota. Nós trabalhava com o que nós tinha. Eu trabalhava com aquele Kichut, cortaram um pau, o cara cortou o pau e eu varei meu pé. Foi por isso que eu não fui pra inauguração ${ }^{25}$.

Acidentes graves com mutilações e até mesmo mortes faziam parte da rotina de trabalhadores na Transamazônica, fossem eles contratados oficialmente pelas grandes empresas ou 
subempreitados, todavia, os últimos ocupavam as funçôes mais expostas à riscos ao passo que não possuíam os equipamentos de segurança, tampouco a assistência mínima necessária. A utilização do expediente da subempretagem e suas consequências nefastas também foram lembradas por seu Edson, que assim como Seu Raimundo, trabalhou na obra como operário da construtora Rabello, mas com registro na Carteira de Trabalho:

Lá (no trecho) tinha gente que trabalhava pra ela, mas o trecho era dela (Rabello). Quem trabalhava na empreiteira era registrado, agora quem não trabalhava registrado trabalhava como gato. Aí não era registrado, trabalhava avulso. Era o cara que prestava serviço para a construtora... era o cara que ajudava lá. Esse cara era o gato. Então esse pessoal não tinha nada, era avulso. Até transporte aqui quando precisava dava um pouco de trabalho porque eles não tinham nada a ver com a empresa (grifo nosso) $)^{26}$.

Ao descrever a rotina de acidentes e ser questionado se havia melhorias ou paradas após os acidentes de trabalho, Seu Edson disse que "não parava nada. A empresa pegava aquele cara, botava lá no caixão. Era normal, ninguém parava não por uma coisa dessas" ${ }^{27}$.

Apesar da construção civil ser notadamente uma das atividades em que mais se morre em serviço, chama a atenção a condição descartável da vida humana em grandes obras desenvolvimentistas como a Transamazônica. Para Achille Mbembe, uma das características do exercício da soberania, em especial por Estados Modernos, "é a capacidade de definir quem importa e quem não importa, quem é "descartável” e quem não é" (MBEMBE, 2016, p.135). Neste sentido, os acidentes de trabalho aqui estudados são entendidos como

a culminância de um longo e duro processo de exploração e das péssimas condições de trabalho a que os trabalhadores são expostos e obrigados a suportar, por falta de outras opções que lhes garantam a sobrevivência. (SILVA, 2015, p. 216).

A banalização dos eventos envolvendo acidentes de trabalho e a precarização ou a falta de atendimento de saúde nos canteiros também pode ser percebida nas falas de outros entrevistados. Seu Dalvâneo, por exemplo, disse que acidentes eram comuns e citou picadas de escorpião, de cobra, acidentes com ferramentas perfurocortantes que implicavam em afastamento longo ou definitivo do trabalhador e até um caso em que o trabalhador, na ausência de atendimento adequado dentro do canteiro de obra, decidiu tratar leishmaniose com uma "chave de fenda incandescente queimando a ferida". A frequência com que ocorriam acidentes e o acometimento de doenças implicava em uma alta rotatividade da mão de obra nos canteiros, o que por sua vez resultava na chegada constante de novos trabalhadores que, por não terem tido tempo para dominar as habilidades necessárias ao desenvolvimento laboral adequado estavam expostos com mais facilidade à reprodução de novos acidentes.

Além de gerar dados estatísticos que subsidiam políticas públicas, o acidente de trabalho,

à medida que reduz ou extingue a capacidade individual do trabalho, para o trabalhador representa a cassação do seu direito de viver dignamente como ser humano ou mesmo do direito à própria vida (CHON; KARSCH; HIRANO; SATO, 1985, p. 37).

A partir de 1972 os boletins informativos da FUNDACENTRO $^{28}$ passaram a apresentar tabelas com uma linha dedicada apenas aos acidentes na região da Transamazônica, quando em regra a apresentação era feita por estados, como vemos no Boletim Informativo de outubro de 1972 (tabela 2) e julho de 1973 (tabela 1).

Sem informaçóes sobre o número de empregados na Transamazônica, o ano de 1972 registrou 554 acidentes, aproximadamente um terço do que foi registrado em todo o Estado do Piauí no mesmo período. Por sua vez o Estado do Piauí possuía 44.879 trabalhadores registrados. No mesmo período foram registradas 554 doenças de trabalho. De acordo com os dados do boletim informativo apenas no estado de São Paulo, maior parque industrial do país, teriam ocorrido mais registros de doenças do trabalho. Para efeito de comparação, o antigo Estado da Guanabara ${ }^{29}$ com mais de um milhão de trabalhadores registrados apresentou 223 
casos, ou seja, menos da metade dos casos registrados em trabalhadores da Transamazônica, onde seguramente o número de trabalhadores registrados não ultrapassava duas dezenas de milhares. Havia uma verdadeira "epidemia" de doenças do trabalho na Transamazônica. Os dados apresentados no boletim, e reproduzidos na tabela 2, também chamam a atenção pela gravidade dos acidentes.

Tabela 1 - Destaques de acidentes de trabalho na Transamazônica

\begin{tabular}{|c|c|c|c|c|c|c|}
\hline \multicolumn{7}{|c|}{ Acidentes de trabalho } \\
\hline $\begin{array}{l}\text { Unidades da } \\
\text { federação }\end{array}$ & $\begin{array}{l}\text { Número de } \\
\text { empregados }\end{array}$ & Típicos & $\begin{array}{c}\text { Doenças de } \\
\text { Trabalho }\end{array}$ & Trajeto & Total & $\begin{array}{c}\% \mathrm{de} \\
\text { acidentados }\end{array}$ \\
\hline Acre & --- & 80 & -- & 1 & 81 & --- \\
\hline Alagoas & 101.019 & 4.763 & -- & 12 & 4.775 & 4,73 \\
\hline Amazonas & 51.310 & 9.023 & -- & 86 & 9.109 & 17,75 \\
\hline Bahia & 396.102 & 68.820 & 3 & 809 & 69.632 & 17,58 \\
\hline Ceará & 95.254 & 11.909 & 148 & 161 & 12.218 & 12,83 \\
\hline Espírito Santo & 104.119 & 20.529 & 1 & 180 & 20.710 & 19,89 \\
\hline Goiás & 82.135 & 6.683 & 57 & 218 & 6.958 & 8,47 \\
\hline Guanabara & 1.099 .640 & 133.294 & 223 & 3.637 & 137.154 & 12,47 \\
\hline Maranhão & 66.963 & 3.434 & 30 & 11 & 3.475 & 5,19 \\
\hline Mato Grosso & 72.114 & 5.420 & -- & 240 & 5.660 & 7,85 \\
\hline Minas Gerais & 675.370 & 104.535 & 128 & 1.915 & 106.578 & 15,78 \\
\hline Pará & 82.345 & 15.240 & 20 & 103 & 15.363 & 18,66 \\
\hline Paraíba & 94.864 & 4.705 & 3 & 105 & 4.813 & 5,07 \\
\hline Paraná & 491.652 & 59.859 & 2 & 987 & 60.848 & 12,38 \\
\hline Pernambuco & 303.555 & 27.313 & 153 & 443 & 27.909 & 9,19 \\
\hline Piauí & 44.879 & 1.559 & --- & 62 & 1.621 & 3,61 \\
\hline Rio G. do Norte & 62.491 & 5.148 & --- & 23 & 5.171 & 8,27 \\
\hline Rio G. do Sul & 563.023 & 175.852 & 105 & 2.375 & 178.332 & 31,67 \\
\hline Rio de Janeiro & 300.358 & 75.548 & 8 & 1.020 & 76.576 & 25,49 \\
\hline Santa Catarina & 274.868 & 53.686 & 255 & 1.235 & 55.176 & 20,07 \\
\hline São Paulo & 2.674 .992 & 669.604 & 712 & 8.897 & 679.213 & 25,39 \\
\hline
\end{tabular}




\begin{tabular}{|l|r|r|r|r|r|r|}
\hline Sergipe & 37.661 & 3.513 & 73 & 43 & 3.629 & 9,64 \\
\hline Distrito Federal & 98.660 & 18.161 & -- & 453 & 18.614 & 18,87 \\
\hline Transamazônica & --- & 554 & 554 & $\cdots$ & 1.108 & $\cdots$ \\
\hline TOTAL & 7.773 .374 & 1.479 .232 & 2.475 & 23.016 & 1.504 .723 & 19,36 \\
\hline
\end{tabular}

Fonte: Boletim Informativo FUNDACENTRO, V. 4, no3, julho de 1973.

Tabela 2 - Acidentes de Trabalho

SEGUROS SOCIAIS - ACIDENTES DE TRABALHO

\begin{tabular}{|c|c|c|c|c|c|c|c|c|}
\hline \multicolumn{9}{|c|}{ 1o semestre 1972} \\
\hline \multirow{3}{*}{$\begin{array}{l}\text { Unidades da } \\
\text { Federação }\end{array}$} & \multirow{3}{*}{$\begin{array}{l}\text { Acidentes } \\
\text { Registrados }\end{array}$} & \multicolumn{5}{|c|}{ Acidentes liquidados } & \multirow[t]{3}{*}{ Morte } & \multirow[t]{3}{*}{ Total } \\
\hline & & \multirow{2}{*}{$\begin{array}{l}\text { Simples } \\
\text { assistência } \\
\text { médica }\end{array}$} & \multirow{2}{*}{$\begin{array}{l}\text { Incapacidade } \\
\text { temporária }\end{array}$} & \multicolumn{3}{|c|}{ Incapacidade permanente } & & \\
\hline & & & & $1 \%$ a $25 \%$ & $\begin{array}{c}30 \% \text { a } \\
60 \%\end{array}$ & $\begin{array}{c}100 \% \text { a } \\
125 \%\end{array}$ & & \\
\hline \multicolumn{9}{|l|}{ Norte } \\
\hline Amazonas & 4.683 & 50 & 3.687 & 95 & 18 & 3 & 7 & 3.860 \\
\hline Pará & 8.439 & 372 & 6.332 & 282 & 52 & --- & 27 & 7.065 \\
\hline Acre & 48 & --- & 26 & --- & 12 & --- & --. & 38 \\
\hline \multicolumn{9}{|l|}{ Nordeste } \\
\hline Maranhão & 1.917 & 17 & 1.561 & 19 & 4 & -.- & 3 & 1.604 \\
\hline Piauí & 1.208 & --- & 1.031 & 33 & 6 & --- & 7 & 1.077 \\
\hline Ceará & 6.761 & 95 & 5.895 & 171 & 77 & 8 & 33 & 6.279 \\
\hline $\begin{array}{l}\text { Rio Grande do } \\
\text { Norte }\end{array}$ & 3.122 & 29 & 2.659 & 85 & 18 & 1 & 10 & 2.802 \\
\hline Paraíba & 2.515 & 58 & 2.084 & 64 & 18 & --- & 8 & 2.232 \\
\hline Pernambuco & 19.196 & 42 & 13.475 & 499 & 200 & 19 & 51 & 14.286 \\
\hline Alagoas & 2.680 & 125 & 2.243 & 30 & 14 & -.- & 10 & 2.422 \\
\hline Sergipe & 2.123 & 136 & 1.784 & 27 & 13 & --- & 12 & 1.972 \\
\hline Bahia & 36.379 & 8.371 & 23.074 & 263 & 71 & 13 & 36 & 31.848 \\
\hline \multicolumn{9}{|l|}{ Sudeste } \\
\hline Minas Gerais & 52.283 & 5.407 & 41.669 & 1.091 & 189 & 26 & 135 & 48.317 \\
\hline
\end{tabular}




\begin{tabular}{|c|c|c|c|c|c|c|c|c|}
\hline Espírito Santo & 12.009 & 860 & 8.120 & 321 & 64 & 2 & 39 & 9.406 \\
\hline Rio de Janeiro & 41.541 & 1.941 & 33.527 & 1.227 & 71 & 10 & 95 & 36.871 \\
\hline Guanabara & 73.430 & 945 & 63.825 & 3.466 & 187 & 33 & 203 & 68.709 \\
\hline São Paulo & 356.302 & 61.326 & 273.526 & 7.801 & 801 & 102 & 425 & 344.008 \\
\hline \multicolumn{9}{|l|}{ Sul } \\
\hline Paraná & 36.037 & 293 & 28.972 & 781 & 138 & 18 & 39 & 30.261 \\
\hline Santa Catarina & 30.781 & 460 & 26.914 & 716 & 501 & 9 & 32 & 28.352 \\
\hline $\begin{array}{l}\text { Rio Grande do } \\
\text { Sul }\end{array}$ & 100.017 & 8.333 & 83.890 & 1.758 & 311 & 15 & 72 & 94.979 \\
\hline \multicolumn{9}{|l|}{ Centro Oeste } \\
\hline Mato Grosso & 3.432 & 23 & 2.403 & 42 & 25 & 2 & 13 & 2.510 \\
\hline Goiás & 3.246 & 40 & 2.788 & 108 & 41 & 3 & 19 & 2.999 \\
\hline Distrito Federal & 9.813 & 9 & 9.561 & 232 & 50 & 36 & 35 & 9.923 \\
\hline Transamazônica & 553 & 92 & 311 & 8 & 2 & -- & 133 & 546 \\
\hline BRASIL & 808.537 & 89.421 & 639.437 & 19.119 & 2.783 & 300 & 1.506 & 752.66 \\
\hline
\end{tabular}

Fonte: Boletim Informativo da FUNDACENTRO, v. 3, Out. 1972, n. 34.

Como vemos na tabela 2 foram registrados na região da Transamazônica 553 acidentes de trabalho no período analisado. Destes apenas 92 resultaram em simples assistência médica, ou seja, a maior parte dos acidentes tiveram maior gravidade. 321 acidentes provocaram incapacidade temporária ou permanente e 133 mortes foram provocadas por acidentes de trabalho na Transamazônica no período computado. Este número corresponde a $24 \%$ do total de acidentes registrados.

Segundo os dados analisados, aproximadamente um a cada quatro acidentados no trabalho que entrou para as estatísticas da Transamazônica naquele primeiro semestre de 1972 acabou perdendo a vida, o que fazia da região, em termos proporcionais, o lugar mais mortífero para trabalhadores da construção civil do país inteiro. São Paulo, região mais industrializada e com o maior número absoluto de acidentes do país, registrou 356.302 acidentes e 425 mortes, o que significa menos de $0,2 \%$ de acidentes fatais. A desproporção correlata entre os dados da Transamazônica e os
Estados da federação são alarmantes. Nesse período, o Estado que registrou a maior letalidade proporcional de acidentes de trabalho foi Goiás, com $0,58 \%$ de acidentes de trabalho que resultaram em mortes. Em outras palavras, significa dizer que, em números redondos, os acidentes na Transamazônica eram quase 50 vezes mais letais do que no Estado de Goiás.

\section{Considerações finais}

As condições de trabalho encontradas pelos trabalhadores da Transamazônica foram, de maneira geral, muito difíceis. As dificuldades passavam pela adaptação ao meio ambiente e se agravavam na medida em que as empresas não cumpriam com suas obrigações legais. $\mathrm{O}$ caso dos trabalhadores aliciados e subcontratados por terceiros era ainda pior, uma vez que constituíram um grupo de seres humanos cujas vidas eram mais descartáveis. 
Entre os trabalhadores que fizeram parte do projeto da Transamazônica há trajetórias individuais que devem ser vistas como tal, todavia, há também um conjunto de similitudes nas experiências que são geradas pela condição e natureza do trabalho imposto. Questôes como superexploração do trabalho, mutilações e mortes nos canteiros de obra, além da imposição de violências simbólicas e físicas fizeram parte da rotina de pessoas anônimas que poucas vezes podem registrar suas impressóes a respeito do processo histórico que protagonizaram.

Completados mais de cinquenta anos do início da obra que foi pensada sob a égide da doutrina de segurança nacional implementada durante a ditadura civil-militar e sustentada sob pressupostos equivocados como a noção de vazio demográfico amazônico e a ameaça da soberania nacional, a Transamazônica que prometeu integrar o Brasil e equacionar os problemas sociais e econômicos que impediam o país de se tornar o "Brasil Grande" deixou um rastro de violações de direitos humanos e degradação ambiental que até hoje repercutem nas demandas socioambientais da região. Os sujeitos anônimos que tiveram suas vidas afetadas pelo empreendimento têm normalmente suas vozes silenciadas nos registros oficiais e daí urge a necessidade de cada vez mais se contar a história dos que construíram caminhos e, não raramente, acabaram encontrando o fim da linha.

\section{Notas}

1 Edital no 36/70 In: Jornal Correio da Manhã, 20/06/1970.

2 A empresa inicialmente indicada para execução foi a Construtora Cristo Redentor, entretanto após dificuldades financeiras teve seu lote dividido entre as empresas S.A. e Construtora Mendes Júnior. Cf. CAMPOS, 2012.

3 Trecho retirado do discurso do Presidente Médici em Recife, 6 de junho de 1970 apud Gomes (1972, p. 8).

$4 \mathrm{O}$ trecho pioneiro de abertura iniciava-se em Estreito-MA, aproveitando o trecho já existente que partia de Cabedelo-PB.

5 A Fundação Centro Nacional de Segurança, Higiene e Medicina do Trabalho (FUNDACENTRO) é um órgão criado pelo Estado brasileiro em 1966 com a finalidade de fazer o Brasil cumprir a resolução no 112 da Organização
Internacional do Trabalho (OIT), que dispóe sobre serviços de medicina do trabalho em um contexto de grande alta nos índices de acidentes do trabalho no país. Em 1978 passou a se chamar Fundação Jorge Duprat Figueiredo de Segurança e Medicina do Trabalho (FUNDACENTRO). Cf. MONTEIRO, 2013)

6 Revista O Cruzeiro 15/09/1971 no 37, p. 236.

7 Disponível na Hemeroteca Digital da Biblioteca Nacional.

8 Gato ou Gaiteiro é o termo pelo qual os habitantes locais se referem ao sujeito que faz a intermediação entre o trabalhador e a empresa contratante. Uma espécie de arregimentador de mão de obra. As pessoas recrutadas por gatos são, normalmente, pouco escolarizadas, exercem tarefas braçais e não são contratadas em acordo com a legislação trabalhista. Por vezes o termo gato também é usado para se referir ao próprio trabalhador recrutado.

9 Correio Braziliense, 25/07/1973. Acervo da Hemeroteca Digital da Biblioteca Nacional. Disponível em:

http://memoria.bn.br/DocReader/DocReader.aspx?bib $=028274 \_02 \&$ Pesq $=\% 22$ visitou $\% 20 u m a \% 20$ serraria\%20d o\%20\%c3\%b3rg\%c3\%a3o\%22\&pagfis=35575 Acesso em: 12 out. 2020.

10 Utilizamos o conceito de violência estrutural tomado de empréstimo de Johan Galtung e replicado por José María Tortosa e Daniel La Parra, para os quais o conceito pode ser aplicável "en aquellas situaciones en las que se produce un daño en la satisfacción de las necesidades humanas básicas (supervivencia, bienestar, identidad o libertad) como resultado de los procesos de estratificación social, es decir, sin necesidad de formas de violencia directa. El término violencia estructural remite a la existencia de un conflicto entre dos o más grupos de una sociedad (normalmente caracterizados en términos de género, etnia, clase, nacionalidad, edad u otros) en el que el reparto, acceso o posibilidad de uso de los recursos es resuelto sistemáticamente a favor de alguna de las partes y en perjuicio de las demás, debido a los mecanismos de estratificación social. (TORTOSA; PARRA, 2003, p. 57). Existe um grande debate historiográfico em torno do conceito de biopoder que não cabe neste trabalho. Sobre as discussões e os limites do conceito, cf. BERTOLINI, 2018.

11 Seu Dão trabalhou na obra da Transamazônica como operador de máquinas pela empresa Queiroz Galvão. No período da entrevista (maio de 2018) estava aposentado pelo DNER e vivia em Uruará-PA, onde é um personagem conhecido por ter protagonizado o primeiro casamento da Transamazônica, sendo noticiado e inclusive recebendo presentes da comitiva presidencial que havia visitado a obra semanas antes. 
12 Entrevista realizada em maio de 2018 na cidade de Uruará-PA.

13 Seu Luis é paranaense de Curitiba. O fato de ter vivido em uma capital do Sul do país permitiu construir uma formação técnica pelo Serviço Nacional de Aprendizagem Industrial (SENAI). Trabalhou na Transamazônica contratado como mecânico na construtora Mendes Jr em uma das primeiras frentes de trabalho. Abandonou a obra e a região e hoje é um pequeno empresário na cidade de Fortaleza-CE. Entrevista realizada na cidade de Fortaleza em fevereiro de 2018.

14 Entrevista concedida a Magno Braga. Petrolina-PE, 16 de julho de 2010.

15 Seu Pedro nasceu no Estado do Goiás e trabalhou na Transamazônica na manutenção de máquinas pela empresa S.A. Paulista. O caso de seu Pedro se assemelha com o de outros trabalhadores que já possuíam algumas experiências em obras rodoviárias anteriores. Trabalhou na Rodobras, empresa pública criada para construção da rodovia Belém-Brasília. Seu Pedro conseguiu se especializar no trabalho e após sair da empresa foi contratado pelo DNER que era responsável pela manutenção da estrada. No período da entrevista (maio de 2018) vivia na região de Marabá-PA e estava aposentado.

16 Entrevista concedida a Magno Braga. Marabá-PA, 17 de maio de 2018.

17 Wilson Quintella foi executivo e presidente $\mathrm{da}$ construtora Camargo Corrêa, responsável pela construção de trecho da Transamazônica.

18 Seu Dalvâneo nasceu em Pernambuco, é engenheiro e trabalhou na obra da Transamazônica como mão de obra altamente especializada por uma empresa subcontratada chamada Astep S.A. Engenheiros consultores. O discurso de Seu Dalvâneo deixa transparecer a diferenciação social que enxerga entre si e os demais trabalhadores que chefiava, além dos privilégios que um grupo muito restrito de trabalhadores altamente qualificados tinham nos canteiros da obra. No período da entrevista vivia na cidade de Olinda-PE, era aposentado e continuava trabalhando como engenheiro.

19 Entrevista concedida a Magno Braga. Olinda-PE, 13 de abril de 2011.

20 Seu Raimundo nasceu no Pará e sua trajetória se confunde com a de grande parte dos trabalhadores que atuaram na obra da Transamazônica. Sem registros oficiais e permanentemente em movimento migratório pela sobrevivência. Tentou viver em lotes da Transamazônica, mas desistiu da vida na Amazônia. Trabalhadores como seu Raimundo foram a maioria envolvida na obra, mas nos dias de hoje são sujeitos mais difíceis de se encontrar pela região, seja pelas constantes movimentações internas, seja por terem sido expostos a um tipo de vida que diminui as chances de envelhecer. No período da entrevista (maio de 2018) vivia na cidade de Goiânia-GO e era aposentado.

21 Entrevista concedida a Magno Braga. Goiânia-GO, 14 de maio de 2018.

22 Destaque da matéria da Revista Manchete citada anteriormente.

23 A entrevista com Seu Dão foi realizada na cidade de Uruará-PA, em maio de 2018, A pequena cidade surgiu após o boom da Transamazônica na década de 1970. As entrevistas realizadas nas cidades amazônicas nos exigiram mais esforço de deslocamento devido às condiçóes locais (Estradas sem condiçóes de trafegabilidade, longas distâncias e o fato de o país ter vivido uma greve geral de caminhoneiros que bloqueou diversas rodovias nacionais em maio de 2018), às longas distâncias e às características naturais da região.

24 Cf. SPERANZA, 2014.

25 Entrevista concedida a Magno Braga. Goiânia-GO, 14 de maio de 2018. Grifo nosso. Gato era como eram chamados os trabalhadores não registrados pelas empresas.

26 Entrevista concedida a Magno Braga. Petrolina-PE, 16 de julho de 2010.

27 Entrevista concedida a Magno Braga. Petrolina-PE, 16 de julho de 2010.

28 No período estudado, a FUNDACENTRO tinha uma publicação regular chamada de Boletim Informativo, aos quais tivemos acesso e onde constam os dados estatísticos acerca dos acidentes de trabalho, das diretrizes e chamamentos para congressos e outras pautas relacionadas à temática. Os dados estatísticos contido nesses boletins são construídos a partir das informações do INPS, o que fazia com que apenas os trabalhadores com carteira de trabalho assinada fossem considerados. 29 Hoje englobado pelo estado do Rio de Janeiro.

\section{Referências}

CAMPOS, Pedro Henrique Pedreira. A ditadura dos Empreiteiros: as empresas nacionais de construção pesada, suas formas associativas e o Estado ditatorial brasileiro, 1964-1985. 2012, $584 \mathrm{f}$. Tese (Doutorado em História) - Programa de Pós-Graduação em História, Universidade Federal Fluminense, Rio de Janeiro, 2012.

CHON, Amélia; HIRANO, Sedi; KARSCH, Ursula S.; SATO, Ademar K. Acidentes de 
Trabalho: Uma forma de violência. Editora Brasiliense, São Paulo, 1985.

CONINGHAM NETTO, John. A ponte sobre o rio Tuerê: Drama na Abertura da Transamazônica. Campinas-SP: Editora Komedi, 2000.

BERTOLINI, Jeferson. O conceito de biopoder em Foucault: apontamentos bibliográficos. Saberes, Natal-RN, v. 18, n. 3, p. 86-100, dez. 2018.

FUNDACENTRO. Boletim Informativo. v. 4, n. 43, julho de 1973.

GOMES, Flávio Alcaraz. Transamazônica: A redescoberta do Brasil. São Paulo: Livraria Cultura Editora, 1972.

MBEMBE, Achille. Necropolítica: biopoder, soberania, estado de exceção, política da morte. Arte \& Ensaios, Rio de Janeiro, n. 32, p. 123-151, jan. 2016.

MENEZES, Fernando Dominience. Enunciados sobre o futuro: ditadura militar, Transamazônica e a construção do "Brasil grande". 2007, 155 f. Dissertação (Mestrado em História) - Programa de Pós-Graduação em História, Universidade de Brasília, Brasília, 2007.

MONTEIRO, Juliana Santos. Fundacentro: Função Social da Política sobre Acidentes de Trabalho no período ditatorial brasileiro (1966-1976). 2013, 139 f. Dissertação (Mestrado em História) - Pontifícia Universidade Católica de São Paulo, São Paulo, 2013.

QUINTELLA, Wilson. Memórias do Brasil Grande: a história das maiores obras do país e dos homens que as fizeram. São Paulo: Saraiva, 2008.
RIBEIRO, Gustavo Lins. O Capital da Esperança: A experiência dos trabalhadores na construção de Brasília. Brasília: Editora da Universidade de Brasília, 2008.

SILVA, Ana Beatriz Ribeiro Barros. Acidentes, adoecimento e morte no trabalho como tema de estudo da História. In: OLIVEIRA, T. B., (Org). Trabalho e trabalhadores no Nordeste: análises e perspectivas de pesquisas históricas em Alagoas, Pernambuco e Paraíba [online]. Campina Grande: EDUEPB, 2015, p. 215- 240.

SILVA, Ana Beatriz Ribeiro Bastos. Corpos para o Capital: acidentes de trabalho, prevencionismo e reabilitação profissional durante a ditadura civil-militar brasileira (1964-1985). Jundiaí: Paço editorial, 2019.

SOUZA, César Augusto Martins de. A estrada invisível: memórias da Transamazônica. 2012, 264 f. Tese (Doutorado em História) - Instituto de Ciências Humanas e Filosofia, Universidade Federal Fluminense, Rio de Janeiro, 2012.

SPERANZA, Clarice Gontarski. Cavando direitos: As leis trabalhistas e os conflitos entre os mineiros de carvão e seus patrôes no Rio Grande do Sul (1940-1954). Porto Alegre: Oikos, 2014.

PARRA, Daniel; TORTOSA, José María. "Violencia estructural: una ilustración del concepto". Documentación Social. n. 131, p. 57-72, 2003. 